\title{
Genotype by environment interaction for area under the disease-progress curve (AUDPC) value in spring barley using additive main effects and multiplicative interaction model
}

\author{
Jan Bocianowski ${ }^{1}\left(\right.$ D $\cdot$ Anna Tratwal $^{2}($ D $) ~$ Kamila Nowosad $^{3}(\mathbb{D})$
}

Received: 19 February 2020 / Accepted: 2 June 2020 / Published online: 9 June 2020

(C) The Author(s) 2020

\begin{abstract}
The objective of this study was to assess genotype by environment interaction for area under disease progress curve values in spring barley grown in South-West Poland by the additive main effects and multiplicative interaction model. The study comprised of 25 spring barley genotypes (five cultivars: Basza, Blask, Antek, Skarb and Rubinek as well as all possible 10 two-way mixtures and 10 three-way mixtures combinations), evaluated at two locations in 4 years (eight environments) in a randomized complete block design, with four replicates. Area under disease progress curve (AUDPC) value of the tested genotypes ranged from 75.3 to 614.3 , with an average of 175.3. In the AMMI analyses, $13.43 \%$ of the AUDPC value variation was explained by environment, $37.85 \%$ by differences between genotypes, and $18.20 \%$ by genotype by environment interaction. The mixture Basza/Skarb is recommended for further inclusion in the breeding program due to its low average AUDPC value (98.8) and is stable (AMMI stability value $=6.65$ ).
\end{abstract}

Keywords Area under disease progress curve $\cdot$ AMMI $\cdot$ Spring barley $\cdot$ Stability

\section{Introduction}

Calculation of the area under the disease-progress curve (AUDPC) as a measure of quantitative disease resistance entails repeated disease assessments (Jeger and Viljanen-Rollinson 2001). Trails related to diseases assessment require work and time to a large extent. There are some limitations (weather, space) how frequently assessments can be made. The use of the calculated AUDPC has increased in recent years and can certainly be recommended when, because of either host phenology or growth, monotonically increasing disease progress is unlikely (Jeger and Viljanen-Rollinson 2001).

Jan Bocianowski

jan.bocianowski@up.poznan.pl

1 Department of Mathematical and Statistical Methods, Poznań University of Life Sciences, Wojska Polskiego 28, 60-637 Poznań, Poland

2 Poland Department of Pests Methods Forecasting and Economy of Plant Control, Institute of Plant Protection - National Research Institute Poznan, Władysława Wegorka 20, 60-318 Poznań, Poland

3 Department of Genetics, Plant Breeding and Seed Production, Wrocław University of Environmental and Life Sciences, Grunwaldzki 24A, 53-363 Wrocław, Poland
Spring barley takes about $10 \%$ of the total grain area annually, and the spring form usually occupies four times more area than the winter form. The advantages for spring barley are the lack of wintering problems and less expenditure on cultivation. The spring barley is characterized by high reliability of yield, which results from less sensitivity to rainfall shortage. The cultivation of spring barley takes place mainly for fodder and brewing purposes. Spring barley is also the basic ingredient of cereal mixes used for fodder purposes.

One of the most important diseases occurring od spring barley in Poland is powdery mildew caused by Blumeria graminis f. sp. hordei. Usually winter barley is more seriously affected than spring barley. B. graminis is a genetically diverse pathogen with different special forms and races.

Environmental conditions strongly influence agricultural production, leading to considerable variations in values of quantitative trait. Such influence is discriminated when experiments are performed in various locations and in different years. Such influence is termed genotype-by-environment (GE) interaction. The presence of GE interaction influences production making the selection of genotypes in a complex process (Becker and Leon 1988; Cooper and DeLacy 1994; Heslot et al. 2014; Hassani et al. 2018). Among various statistical techniques used for evaluating GE interaction, the most frequently used is te Additive Main-effects and Multiplicative 
Interaction (AMMI) model (Gauch 1988; Zobel et al. 1988). The AMMI model uses analysis of variance (ANOVA) and principal component analysis (PCA) to achieve a better understanding of GE interaction, its causes and consequences. A PCs model is fitted to the residuals from the ANOVA and the resulting scores, called the I (for interaction) PCA (IPCA) are calculated for both the genotypes and the trials or environments.

The objective of this paper was to assess GE interaction for area under the disease-progress curve (AUDPC) in spring barley by the AMMI model.

\section{Material and methods}

Field experiments with spring barley were carried out at two locations: Bąków (5042’ N, $\left.18^{\circ} 28^{\prime} \mathrm{E}\right)$ and Kościelna Wieś $\left(51^{\circ} 47^{\prime} \mathrm{N}, 18^{\circ} 00^{\prime} \mathrm{E}\right)$ in 4 years: $2010-2013$. The two sites differed in terms of soil and weather conditions. Cultivars of spring barley (Basza, Blask, Antek, Skarb and Rubinek) as well as all possible two-way mixtures and three-way mixtures combinations were cultivated on plots of $10 \mathrm{~m}^{2}$ (Baków) and $16.5 \mathrm{~m}^{2}$ (Kościelna Wieś) in the randomized complete block designs with four replicates. The ratio of cultivar components in mixtures was $1: 1$ or $1: 1: 1$. Rows spacing in plots $-12.5 \mathrm{~cm}$, seed drill type - Oyord (Bąków), SPZ 1.5/2 (Kościelna Wieś). Fertilization - N: 60-60 kg/ha, P: 30-40 kg/ha, K: $50-60 \mathrm{~kg} /$ ha. Soil types: podsolic soil and leached brown soil (Baków); leached brown soil and acid brown soil (Kościelna Wieś). No fungicide treatments were applied in the experiments.

Natural powdery mildew infections on spring barley plants were assessed every 7-10 days during the growing season. The intensity of the disease infection was assessed using following, 9-grade scale: where" 9" full resistance (no symptoms of the disease, while)" 1 " indicated full susceptibility Tratwal and Bocianowski (2018). The obtained results were expressed as a percentage value of damage caused by the disease to particular plants of pure cultivars and mixtures. Analyses were carried out on individualy-converteed percentage value.

The area under the disease-progress curve (AUDPC) value was calculated according to formula (Jeger and ViljanenRollinson 2001; Tratwal and Bocianowski 2014):

$A U D P C=\sum_{i=1}^{n}\left\{\left(\frac{y_{i}+y_{i-1}}{2}\right)\left(x_{i}-x_{i-1}\right)\right\}$,

where AUDPC is the area under disease progress curve, $y_{i}$ is the percentage of visible infected area $\left(y_{i} /\right.$ 100) at the $i$-th observation, $x_{i}$ - day of the $i$-th observation, and $n$ - the total number of observations (modified from Shaner and Finney 1977).
In the case of AMMI analysis, PCA is applied to the GE interaction effects only after some preliminary verifications are made based on ANOVA analysis. Two-way ANOVA was carried out to determine the effects of genotypes $(G)$, environments (E) and GE interaction on the variability of AUDPC. Least-squares means were simultaneously produced for the AMMI model. The model first fits additive effects for the main effects of $\mathrm{G}$ and $\mathrm{E}$ followed by multiplicative effects for GE interaction by PCA. The AMMI model (Gauch and Zobel 1990; Nowosad et al. 2017) is given by:

$y_{g e}=\mu+\alpha_{g}+\beta_{e}+\sum_{n=1}^{N} \lambda_{n} \gamma_{g n} \delta_{e n}+Q_{g e}$,

where $y_{g e}$ is the AUDPC value mean of genotype $g$ in environment $e, \mu$ - the grand mean, $\alpha_{g}$ - the genotypic mean effects, $\beta_{e}$ - the environmental mean effects, $N$ - the number of PCA axis retained in the adjusted model, $\lambda_{n}$ - the square root of the eigenvalue of the PCA axis $n, \gamma_{g n}$ - the genotype score for PCA axis $n, \delta_{e n}$ - the environment score eigenvector for PCA axis $n, Q_{g e}$ - the residual. The AMMI stability value (ASV) was used to compare the stability of genotypes as described by Purchase et al. (2000):

$A S V=\sqrt{\left[\frac{S S_{I P C A 1}}{S S_{I P C A 2}}\left(I P C A_{1}\right)\right]^{2}+\left(I P C A_{2}\right)^{2}}$,

where $S S$ is the sum of squares, IPCA1 and IPCA2 are the first and the second interaction $\mathrm{PC}$ axes, respectively; and the $\mathrm{IPCA}_{1}$ and IPCA 2 scores were the genotypic scores in the AMMI model. The higher the IPCA score, either negative or positive, the more specifically adopted a genotype is to certain environments. Lower ASV score indicate a more stable genotype across environments. For the AMMI analysis, statistical package GenStat v. 18.2 was used.

\section{Results}

Obtained result indicated that the main effects of genotype and environment as well as GE interaction were highly significant $(P<0.001)$. The genotypes main effect explained $37.85 \%$ of the AUDPC value variation, environment main effect $13.43 \%$, while the effects of GE interaction - $18.20 \%$ (Table 1). The IPCA1 accounted for $76.03 \%$ of the variation caused by interaction, while IPCA2 accounted for $-13.18 \%$ on the variation of AUDPC value. The average AUDPC values of the tested genotypes varied from 75.3 (for Basza/ Rubinek) to 614.3 (for Antek) throughout the eight environments, with an average of 175.3. The average AUDPC value per location also varied from 52.1 in Kościelna Wieś 2012, to 290.4 in Kościelna Wieś 2013. 
Table 1 Analysis of variance of main effects and interactions for spring barley AUDPC value

\begin{tabular}{llllll}
\hline Source of variation & d.f. & Sum of squares & Mean squares & $\begin{array}{l}F \text { - } \\
\text { statistic }\end{array}$ & Variability explained (\%) \\
\hline Genotypes & 24 & $9,521,516$ & 396,730 & $32.29^{* * *}$ & 37.85 \\
Environments & 7 & $3,379,170$ & 482,739 & $19.35^{* * *}$ & 13.43 \\
Interactions & 168 & $4,579,488$ & 27,259 & $2.22^{* * *}$ & 18.20 \\
IPCA 1 & 30 & $3,481,705$ & 116,057 & $9.45^{* * *}$ & 76.03 \\
IPCA 2 & 28 & 603,453 & 21,552 & $1.75^{*}$ & 13.18 \\
Residuals & 84 & 303,615 & 3614 & 0.29 & \\
Error & 576 & $7,077,182$ & 12,287 & & \\
\hline
\end{tabular}

*** $P<0.001$. IPCA, principal component of interaction
The AMMI1 biplot (Fig. 1) shows the stability of genotypes and environments, as well as specific GE interactions. Among the tested genotypes, IPCA 1 values ranged from -22.069 (Antek) to 7.137 (Basza/Blask/Skarb), while among tested environments ranged from -22.697 (Kościelna Wieś 2013) to 13.023 (Kościelna Wieś 2012) (Fig. 1). Stability of genotype is considered as consistent reaction to changing environmental conditions, biotic and abiotic stresses, agronomic factors as well as weather conditions. Figure 2 presents the biplot for AUDPC values. The cultivar Antek and mixture Antek/Skarb interacted positively with the KW13 and B13 locations, but negatively with the KW11, KW12 and B11 (Figs. 1 and 2). Mixtures $\mathrm{A} / \mathrm{Bl} / \mathrm{R}$ and $\mathrm{A} / \mathrm{Ba} / \mathrm{R}$ interacted positively with the KW10 location, but negatively with the B10 and B11 locations. Some genotypes have high adaptation; however, most of them have specific adaptability. AMMI stability values (ASV) revealed variations in AUDPC values stability among the 25 genotypes (Table 2). According to
Purchase et al. (2000), a stable variety is defined as one with ASV value close to zero. Consequently, the cultivars Skarb (with ASV of 0.37) and Blask (1.45) as well as mixtures Blask/Rubinek (2.83), Antek/Basza/Skarb (3.69) and Antek/ Rubinek (4.22) were the most stable, while the cultivar Antek (127.45) and mixtures Antek/Skarb (63.38) and Basza/Blask/ Skarb (41.32) were the least stable (Table 2). The mixture Basza/Skarb, with low average AUDPC values (98.8) and good stability (ASV $=6.65$ ) is recommended for further inclusion in the breeding program (Tab. 2, Fig. 2).

\section{Discussion}

Varieties resistant to diseases play a very important role in cultivation and protection of cultivated plants. In modern cereal cultivation, within intensive conventional farming, next to constant modernization of production technology, one may
Fig. 1 Biplot for genotype by environment interaction of AUDPC value in spring barley cultivars and their mixtures in eight environments (two locations in 4 years), showing the effects of primary and secondary components (IPCA 1 and IPCA 2, respectively)

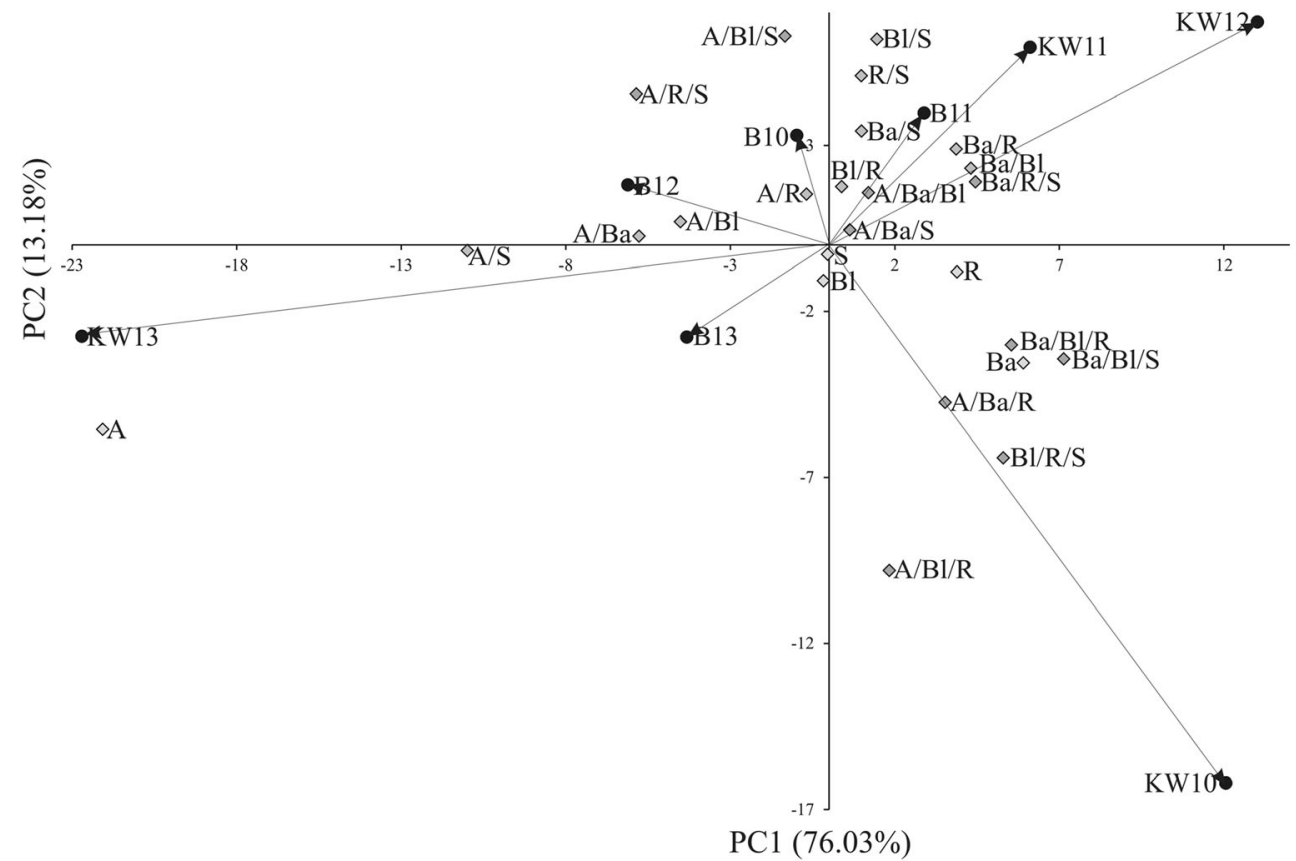


Fig. 2 Biplot for the primary component of interaction (IPCA

1) and average AUDPC value.

Vertical line at the centre of biplot is the general grand mean

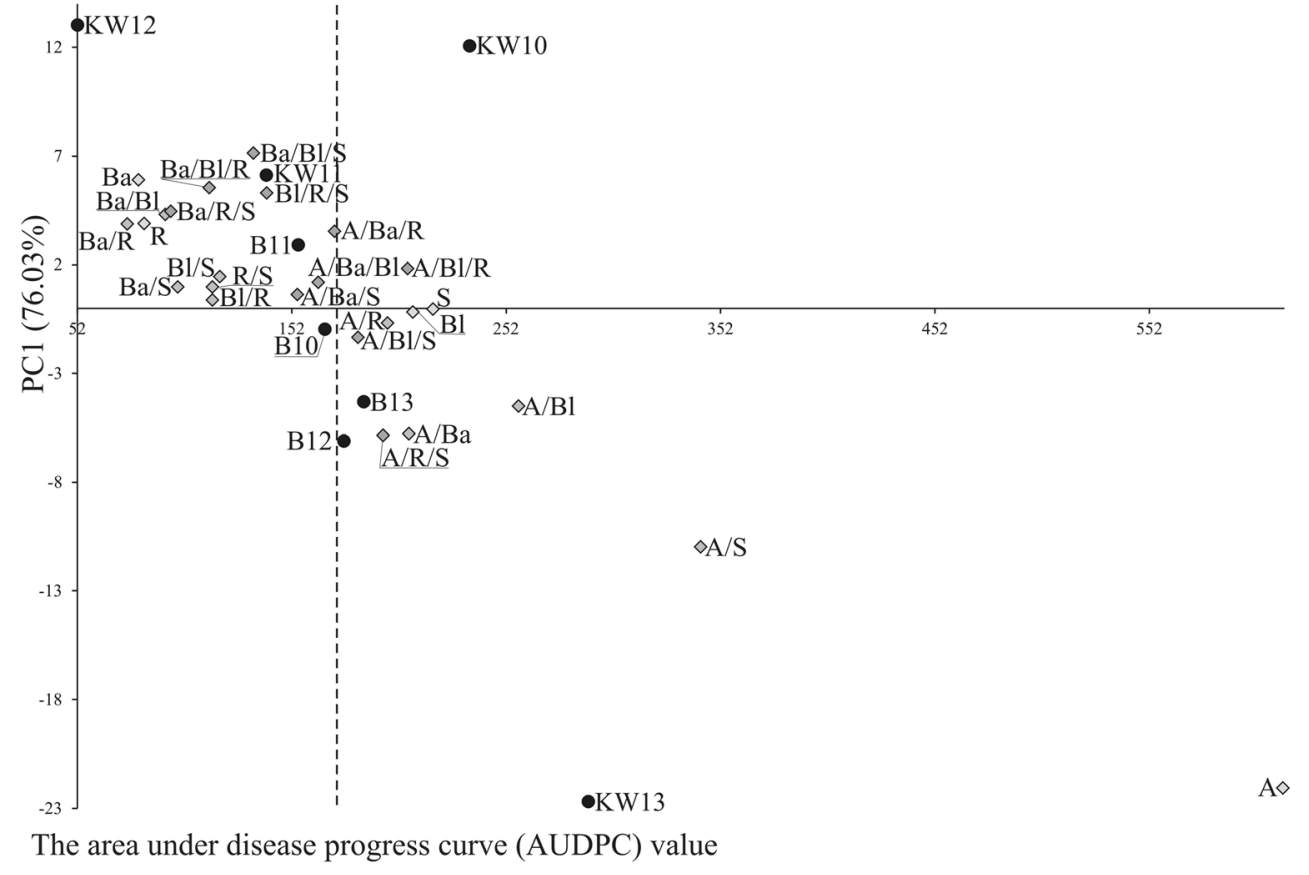

observe a disadvantageous practice of genetic narrowing of cultivated plants and making them more uniform. More and more often one sees large area farms which year after year grow the same species and varieties of cultivated plants in monocultures. From an organizational standpoint it is preferable, but in intensive cereal production one may observe a narrowing of biodiversity, increased sensitivity of the crops to diseases and pests, as well as sensitivity to environment changes. Big areas of single varieties with similar or identical types of resistance to diseases foster fast spread of single physiological strains of pathogens. One of the cheaper and relatively easy ways of diversifying and at the same time increasing the durability of genetic resistance of modern varieties in production conditions is cultivating them in different types of variety mixtures (two or three - ways mixtures). Cultivation of cereal in mixtures restores biodiversity, which thanks to the distinct features of introduced varieties allows for better use of natural diversity of environment and a sustainable agricultural development. Unlike in the case of variety monocultures, in the genetically diversified mixed varieties we may observe different biological (genetic and epidemiological) and ecological mechanisms of disease reduction (Tratwal et al. 2007; Finckh et al. 2000; Tratwal and Walczak 2010). The most important of those mechanisms is resistant plants acting as physical "barriers" for a part of avirulent fomites, induced resistance (biological immunity); the differences in the levels of partial resistance of mixed varieties or interactions between diseases (epidemics) and ecological factors (phenomena of complementation, compensation, competition, aggression and tolerance).

Improved health along with different ecological nondisease related factors limit the need to apply expensive and

Table 2 The AMMI stability value (ASV) of tested spring barley cultivars and their mixtures

\begin{tabular}{|c|c|c|c|c|c|c|c|c|}
\hline Cultivars & Code & ASV & Two-way mixtures & Code & ASV & Three-way mixtures & Code & ASV \\
\hline Basza & $\mathrm{Ba}$ & 34.26 & Basza/Blask & $\mathrm{Ba} / \mathrm{B} 1$ & 24.98 & Antek/Basza/Blask & $\mathrm{A} / \mathrm{Ba} / \mathrm{Bl}$ & 7.08 \\
\hline Blask & $\mathrm{B} 1$ & 1.45 & Antek/Basza & $\mathrm{A} / \mathrm{Ba}$ & 33.28 & Antek/Blask/Skarb & $\mathrm{A} / \mathrm{B} 1 / \mathrm{S}$ & 9.96 \\
\hline Antek & $\mathrm{A}$ & 127.45 & Basza/Skarb & $\mathrm{Ba} / \mathrm{S}$ & 6.65 & Antek/Basza/Rubinek & $\mathrm{A} / \mathrm{Ba} / \mathrm{R}$ & 20.93 \\
\hline Skarb & $\mathrm{S}$ & 0.37 & Basza/Rubinek & $\mathrm{Ba} / \mathrm{R}$ & 22.52 & Antek/Blask/Rubinek & $\mathrm{A} / \mathrm{B} 1 / \mathrm{R}$ & 14.43 \\
\hline \multirow[t]{6}{*}{ Rubinek } & $\mathrm{R}$ & 22.47 & Antek/Blask & $\mathrm{A} / \mathrm{B} 1$ & 26.05 & Antek/Basza/Skarb & $\mathrm{A} / \mathrm{Ba} / \mathrm{S}$ & 3.69 \\
\hline & & & Antek/Skarb & $\mathrm{A} / \mathrm{S}$ & 63.38 & Blask/Rubinek/Skarb & $\mathrm{B} 1 / \mathrm{R} / \mathrm{S}$ & 31.23 \\
\hline & & & Antek/Rubinek & $\mathrm{A} / \mathrm{R}$ & 4.22 & Basza/Blask/Rubinek & $\mathrm{Ba} / \mathrm{Bl} / \mathrm{R}$ & 32.12 \\
\hline & & & Blask/Skarb & $\mathrm{Bl} / \mathrm{S}$ & 10.45 & Antek/Rubinek/Skarb & $\mathrm{A} / \mathrm{R} / \mathrm{S}$ & 34.07 \\
\hline & & & Blask/Rubinek & $\mathrm{Bl} / \mathrm{R}$ & 2.83 & Basza/Blask/Skarb & $\mathrm{Ba} / \mathrm{Bl} / \mathrm{S}$ & 41.32 \\
\hline & & & Rubinek /Skarb & $\mathrm{R} / \mathrm{S}$ & 7.63 & Basza/Rubinek/Skarb & $\mathrm{Ba} / \mathrm{R} / \mathrm{S}$ & 25.77 \\
\hline
\end{tabular}


environment unfriendly fungicide treatments. Thanks to a better use of habitat and agrotechnical conditions mixtures show higher and more stable yielding when compared to that of the varieties of which they are composed. The AMMI stability values for mixtures are better than for cultivars. The ASVs for two-way mixtures ranged from 2.83 (for Blask/Rubinek) to 63.38 (for Antek/Skarb) with an average of 20.20. For three-way mixtures the ASV ranged from 3.69 (for Antek/ Basza/Skarb) to 41.32 (for Basza/Blask/Skarb) with an average of 22.06. The ASVs for cultivars ranged from 0.37 (for Skarb) to 127.45 (for Antek) with an average of 37.20 (Table 2).

In our study we observed negative linear correlation between AUDPC values and PC1 values (Fig. 2). This means that the genotypes with higher AUDPC values had the more negative $\mathrm{PC} 1$ values, so more variable genotypes across environments are the most susceptible (which makes fully biological sense).

To the best of our knowledge, this is the first research which using additive main effects and multiplicative interaction model to analysis genotype-by-environment interaction for area under the disease-progress curve value in spring barley. AMMI biplot's graphic analysis provides relatively simple analysis for breeding researchers. Based on the data, it allows conclusions to be drawn concerning phenotypic stability, genotype behavior, genetic divergence between genotypes, and environments with optimal performance (Tolessa 2015; Abakemal et al. 2016; Sa'diyah and Hadi 2016). The AMMI model is one of the most widely used statistical tools in the analysis of genotype-by-environmental interaction. AMMI model permits to determine stability, multienvironments and determining the best adapted genotype to some environment. AMMI analyses revealed significant genotype-by-environment interaction with respect to AUDPC values.

\section{Compliance with ethical standards}

Conflict of interest The authors declare that they have no conflict of interest.

Open Access This article is licensed under a Creative Commons Attribution 4.0 International License, which permits use, sharing, adaptation, distribution and reproduction in any medium or format, as long as you give appropriate credit to the original author(s) and the source, provide a link to the Creative Commons licence, and indicate if changes were made. The images or other third party material in this article are included in the article's Creative Commons licence, unless indicated otherwise in a credit line to the material. If material is not included in the article's Creative Commons licence and your intended use is not permitted by statutory regulation or exceeds the permitted use, you will need to obtain permission directly from the copyright holder. To view a copy of this licence, visit http://creativecommons.org/licenses/by/4.0/.

\section{References}

Abakemal D, Shimelis H, Derera J (2016) Genotype-by-environment interaction and yield stability of quality protein maize hybrids developed from tropical-highland adapted inbred lines. Euphytica 209: 757-769

Becker HC, Leon J (1988) Stability analysis in plant breeding. Plant Breed 101:1-23

Cooper M, DeLacy IH (1994) Relationships among analytical methods used to study genotypic variation and genotype-by-environment interaction in plant breeding multi-environment experiments. Theor Appl Genet 88:561-572

Finckh MR, Gacek ES, Goyeau H, Lannou C, Merz U, Mundt CC, Munk L, Nadziak J, Newton AC, de Vallavieille-Poppe C, Wolfe MS (2000) Cereal variety and species mixtures in practice, with emphasis on disease resistance. Agronomie 20:813-837

Gauch HG (1988) Model selection and validation for yield trials with interaction. Biometrics 44:705-715

Gauch HG, Zobel RW (1990) Imputing missing yield trial data. Theor Appl Genet 79:753-761

Hassani M, Heidari B, Dadkhodaie A, Stevanato P (2018) Genotype by environment interaction components underlying variations in root, sugar and white sugar yield in sugar beet (Beta vulgaris L.). Euphytica 214:79

Heslot N, Akdemir D, Sorrells ME, Jannink JL (2014) Integrating environmental covariates and crop modeling into the genomic selection framework to predict genotype by environment interactions. Theor Appl Genet 127:463-480

Jeger MJ, Viljanen-Rollinson SLH (2001) The use of the area under the disease-progress curve (AUDPC) to assess quantitative disease resistance in crop cultivars. Theor Appl Genet 102:32-40

Nowosad K, Liersch A, Poplawska W, Bocianowski J (2017) Genotype by environment interaction for oil content in winter oilseed rape (Brassica napus L.) using additive main effects and multiplicative interaction model. Indian J Genet Pl Br 77(2):293-297

Purchase JL, Hatting H, van Deventer CS (2000) Genotype $\times$ environment interaction of winter wheat (Triticum aestivum L.) in South Africa: II. Stability analysis of yield performance. South African J Plant and Soil 17:101-107

Sa'diyah H, Hadi AF (2016) AMMI model for yield estimation in multienvironment trials: a comparison to BLUP. Agric Agric Sci Proc 9: 163-169

Shaner G, Finney RE (1977) The effect of nitrogen fertilization on the expression of slow-mildewing resistance in Knox wheat. Phytopathology 67(12):1833-1837

Tolessa TT (2015) Application of AMMI and Tai's stability statistics for yield stability analysis in faba bean (Vicia faba L.) cultivars grown in central highlands of Ethiopia. J Plant Sci 3(4):197-206

Tratwal A, Bocianowski J (2014) Blumeria graminis f. sp. hordei virulence frequency and the powdery mildew incidence on spring barley in the Wielkopolska province. J Plant Protect Res 54(1):28-35

Tratwal A, Law J, Philpott H, Horwell A, Garner J (2007) The possibilities of reduction of winter barley chemical protection by growing variety mixtures. Part I Effect on powdery mildew level. J Plant Prot Res 47(1):65-77

Tratwal A, Walczak F (2010) Powdery mildew (Blumeria graminis) and pest occurrence reduction in spring cereals mixtures. J Plant Prot Res 50(3):372-377

Tratwal A, Bocianowski J (2018) Cultivar mixtures as part of integrated protection of spring barley. J Plant Dis Prot 125:41-50

Zobel RW, Wright MJ, Gauch HG (1988) Statistical analysis of yield trial. Agron J 80:388-393 